\title{
The Bridge to Learning is You The Teacher!
}

\author{
Dr. Charles E. Notar (Emeritus) \\ Jacksonville State University \\ Dr. Stefanie R. Sorbet \\ University of Central Arkansas
}

\begin{abstract}
Teachers in today's classrooms are called to "build a bridge" in order to best meet the needs of their students. Through organizing a classroom, building procedures and rules, fostering intrinsic motivation in students, providing engaging lessons that attain meaningful objectives all while self-reflecting and adjusting along the way are just some of the steps taken by classroom teachers each day in order to best "build a bridge" and meet their students' needs. Teachers with well-planned and thoughtfully organized classrooms that are constructed with a foundation of support, lead students with routines to succeed. Through accepting feedback and engaging in self-reflection, teachers can adjust lessons and management techniques throughout the school year based on students' response and achievement. This article provides a guided approach for teachers from setting up the classroom, establishing rules and procedures, to the organization and delivery of content area in a manner that best supports the successes of all students involved.
\end{abstract}

Keywords: Classroom Arrangement, Instructional Models, Instructional Time, Learning Activities, Organizational patterns, Presence and Proximity, Reflection, Procedures, Rules, Intrinsic Motivation, Routines, Teaching

\section{INTRODUCTION}

Most new teachers and some veteran ones too do not want to admit ownership in student misbehavior due to the simple fact that their lessons may not be engaging. With this as a starting point we would like to provide some helpful mastery of teaching organizational patterns to engage your students. Teachers provide the setting to propel students forward. We take them from where they are to where they want to go. We should never lose perspective that outcomes and consequences in the classroom should be positive.

A day in a classroom starts before the students arrive, while they are there and then when they are leaving. The before, during and after theme is the organizational pattern of this article. The authors would like to start with a picture that illustrates the title of the article. 


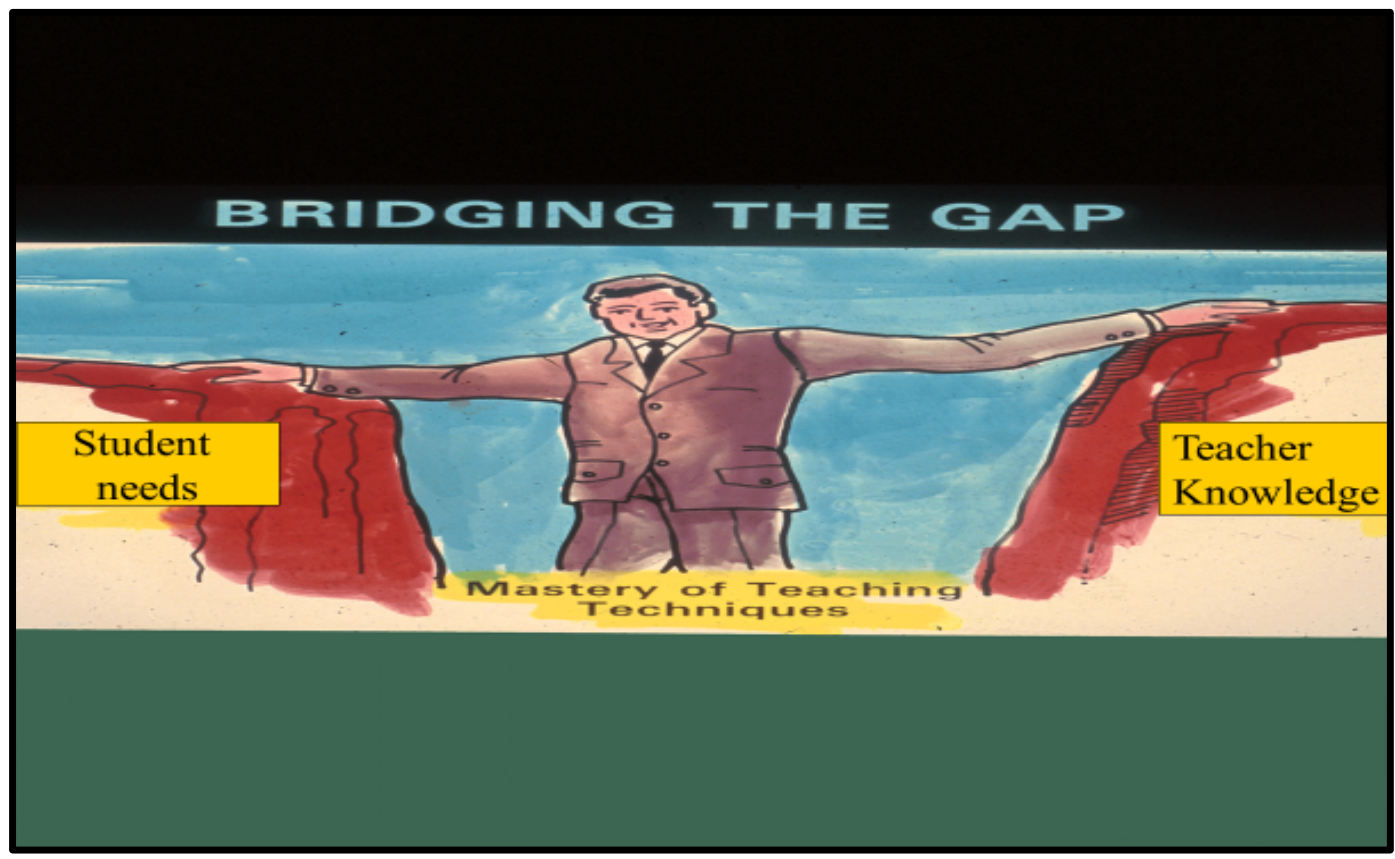

\section{DRAFTING THE DESIGN}

\section{Classroom Arrangement}

The classroom arrangement plays a big part in the behavior and attitude of the students in that setting. Classroom arrangement determines several factors that come into play in instruction. Access to instructional material by you and the students, your ability to interact with students, and configuration of the basic classroom arrangement to fit your methods of instruction are but a few. Figure 1 is an example of an Elementary Classroom with Figure 2 showing points for observation of students while teaching.

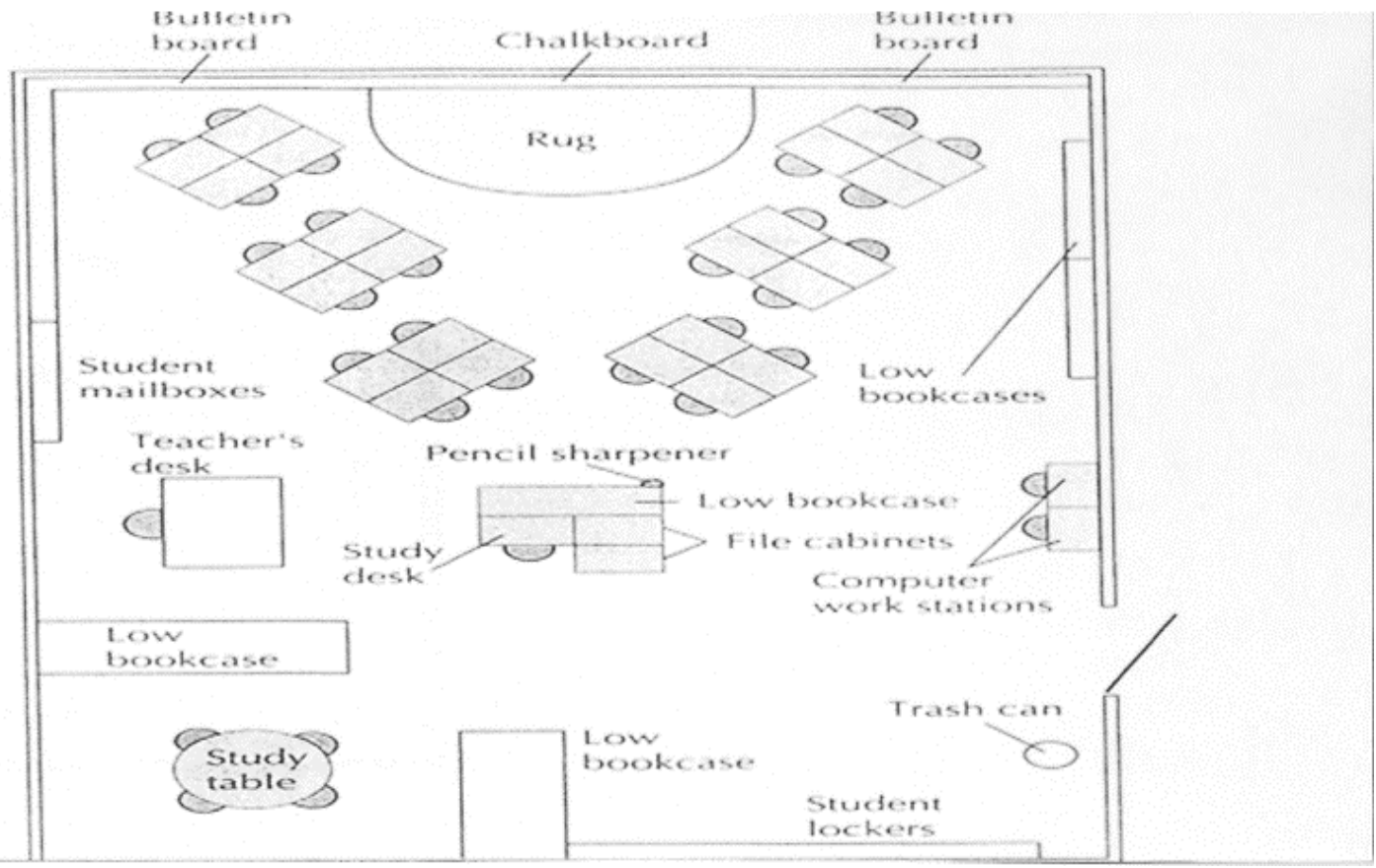

Figure 1: Elementary classroom by Cruickshank, et al., 2006, 380-381. 


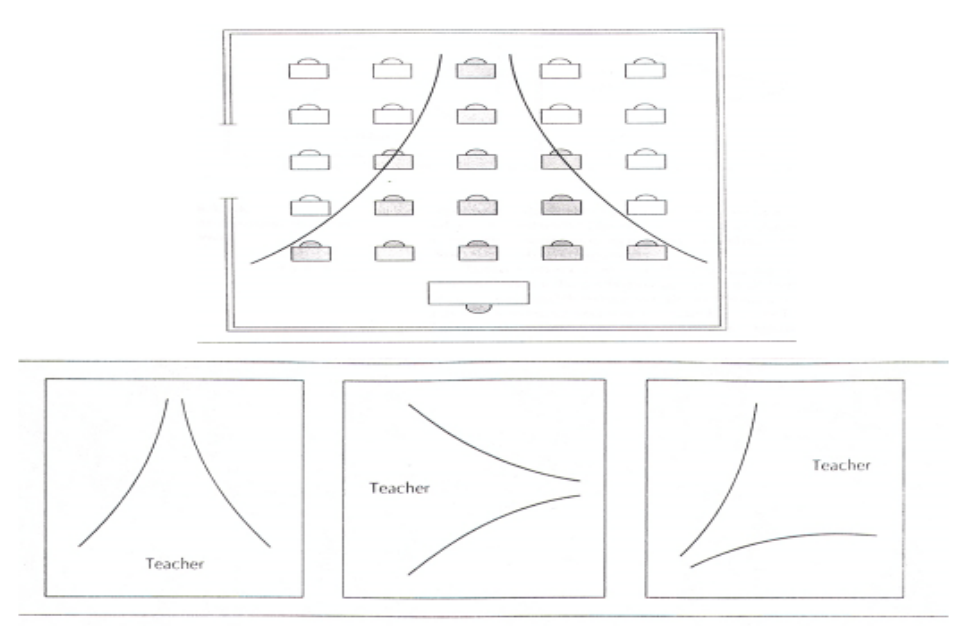

Figure 2: Teaching positions by Cruickshank, et al., 2006, 377-378.

\section{Teaching Positions and Flow}

When arranging your classroom you should make it easy to see students. There is an old saying about "walking a mile in my shoes." As teachers we should walk several miles a day because we should never sit at the desk while students are present. Your presence is very important. You will be observed by your students, they will "size you up", and that first impression will become a lasting one. Students will watch your every move, evaluate your reactions, and assess your attitudes toward them while looking for clues to determine the type of teacher you are. When you are accessible for questions, clarification and reinforcement of positive behavior, you send a message that you are there for them.

Pathways facilitate traffic flow (and your movement around the room) to organize students into pairs, triads, and small groups and make it easy to see all presentations and demonstrations. Frequently used materials should be easily accessible and every square inch of wall space should help immerses the student into the content area(s). Caution however should be taken so the room does not provide or highlight unnecessary distractions.

\section{Seating arrangement}

Allowing students the choice to find their seat in the class from the first day of school fosters a welcoming environment with choices. In order to become acquainted with your students' names as quickly as possible prior to the school year getting underway, a teacher may create a seating chart based on where the students' choose to sit. A seating chart has the layout of the classroom with students' names written where they are seated. This is a great reference tool for teachers to utilize while learning students' in the classroom. After about the third day, the teacher communicates to the students that this will be their seat for the time they are in the classroom unless altered by the teacher. The teacher explains that where they are seated is their responsibility and that their behavior was an investment in that seat. Along with a seating arrangement, the teacher should also have a strategic location if necessary for those who may need to be separated from their group on occasion. This can be the student's go to place to minimize distraction and best support a positive learning environment. 


\section{Presence and Proximity}

It cannot be emphasized enough that you must keep in mind proximity of teacher to students. Maximizing your proximity to minimize problems. A teacher's discipline problems are directly proportional to the distance from the students. Prepare floor space - arrange your desks and materials to facilitate proximity control by Constant movement around the class both as you are teaching and as they are working in group activities.

Standing beside the desk of a student who is talking as you move around the room while continuing to give directions will usually cause the student to stop the disruption. As a rule, people, especially secondary school students, don't want you in their personal space. They'll stop the misbehavior just to get you to move on. While you can say something out loud that will usually disrupt the whole class so use non-verbal communication \& eye contact $(13,14)$.

\section{Procedures and Routines}

\section{THE CONSTRUCTION OF SUPPORTS}

During the first two weeks of the school year a teacher should begin to establish routines and procedures for how they want the classroom to run. This includes expectations of student behaviors and procedures for the way things are operated in the classroom. Harry Wong says that within the first two weeks of school we are not to teach subjects but we are to teach procedures (Wong, 2009). In K-12 grades, procedures are to be taught, practiced and reviewed until students are familiar and understand what is expected of them in all aspects of the classroom. Procedures are how the teacher expects things to be done and after the students understand and practice these procedures, they become routines.

Since there is relatively little instructional time to waste, teachers must teach procedures in order to set expectations and minimize any confusion and disruption. When students know what to expect and follow a pattern each day, activities and lessons go smoother and procedures become automatic. Students expect what is coming and follow procedures out of habit. Your routines are the basics of the way your class functions. There are four types of classroom procedures or routines. These procedures include: management, transition, activity, and instructional (Cruickshank, et al., 2006; Lester, et al., 2017).

Management routines involve nonacademic matters such as distributing and collecting materials and papers, leaving and entering the room, making transitions between activities and classes, cleaning the room. and taking attendance. They are the nuts and bolts of a smoothly functioning classroom.

Transitions are related to times when the teacher wants the students to change from one activity to the next. Transitions are frequent classroom events that should take around 30 seconds and not minutes. Transitional times may include: sharing time, silent reading, setting up for cooperative groups, games, etc.

Activity routines pertain to how an activity will be conducted and includes content, structure and sequence of the activity and the materials the student will need. 
Notar, C. E., \& Sorbet, S. R. (2020) The Bridge to Learning Is You The Teacher! Advances in Social Sciences Research Journal, 7(4) 462-482.

Instructional routines establish what the teacher will do while teaching such as giving directions, demonstrating, instructing, monitoring, reviewing, and questioning students.

Teachers typically develop routines to begin and end the day or class period, to regulate use of materials and equipment, and to guide transitions, group work, seatwork, and teacher-led activities. They know what's coming and do it out of habit. This means that for some activities and portions of the class time, they are on automatic. A smooth-running classroom has procedures put into place so that the students are aware of expectations. A teacher with procedures implemented within his or her classroom minimizes distractions and maximizes instructional time.

\section{Example of a procedure:}

\section{Entering the room at the beginning of the day}

Students are to enter the room quietly. Student assignments are to be placed in the assignment bin. Students will be seated and begin the opening bell assignment on the board.

Other procedures to consider establishing: (list is inclusive and appropriate grades K-12)

- Asking questions

- Missing assignments

- Make-up work

- Heading papers

- Writing on the back of papers

- Neatness and legibility

- Incomplete assignments

- Turning in late work

- Whole class attention, quieting the class, or call backs

- Collecting papers

- Taking attendance
- Broken pencils/sharpening pencils

- Students needing assistance during seatwork

- Restroom privileges

- Procedures as to when to get out of seat

- No textbook, paper, pencil, etc.

- Dismissing class to recess, lunch, end of day, etc.

- Accessing Chromebooks, iPads, technology and returning them daily.

While it is important to clearly communicate and model classroom procedures, your students feel good about the classroom arrangement and routines. An example of the students feeling good about your procedures may be; a teacher always started with the first row going to line up for lunch then proceeded two, three, etc. Students in rows two etc. thought that was unfair. The teacher then decides to call for row one on Monday first, then on Tuesday row two would be first, etc. This change amazingly may change the attitude for lining up for lunch. Your students do have a say and usually have good suggestions... listen.

Once you have established your routines and presence in your classroom, you can selectively go to "planned ignoring." Students will do many things during class that are of such short duration or are so insignificant that they simply should be overlooked or ignored. It won't be that you don't see it, but that you have chosen to ignore it. If a behavior is not a violation of one of your rules, or if reacting to it would interrupt a lesson or call unwanted attention to it. It is wise as a classroom teacher to choose your own battles. 


\section{Nonverbal Cues and Signals}

Sometimes a teacher will use nonverbal cues or signals to indicate to a student that some behavior should stop. It might be a gentle tap on a student's desk, putting a finger to your lips to indicate that a student should stop talking, or merely pointing at the trash basket to indicate something should be thrown away. Nonverbal cues or signals work well to avoid disrupting the entire class when the teacher is trying to redirect one or a few students. For example, a teacher may have posted a numbered list of classroom rules on the wall next to the door. When moving about the classroom the teacher notices a student who is off-task. The teacher walks by and whispers the number of the rule that was not being followed to the student without attracting any other attention and without public embarrassment and moves on. The student being redirected recognizes the teacher attempting to support him or her through positive redirection, receives the message and changes his or her behavior $(11,12)$.

\section{Classroom Rules}

A teacher who sets expectations in the classroom allows students to work within a productive learning environment. At the beginning of the school year, teachers should determine three to five classroom rules to keep students safe and maximize their instructional time. Rules should focus on the positive, and negative words such as not, no, never, are typically avoided. To allow for choice and some ownership of the classroom community, teachers may decide to establish three of the five rules themselves while allowing input from the class of students to create the remaining two rules. Below are three examples of classroom rules:

1. I will come to class with all my needed assignments, papers, and supplies daily.

2. I will follow all school wide rules.

3. I will respect my classmates and my teacher's property.

\section{Classroom Consequences}

A teacher sets non-punitive consequences that match the rules of the class. Beginning teachers consider what they will use. According to Denton, teachers should utilize reinforcing, reminding and redirecting language when working with students (2013). A look at consequences as non-punitive may be a different approach than what is typically utilized. First and foremost, teachers should begin by reinforcing the rules and procedures that have been established in the classroom. Teachers then remind the students of the rules and procedures when a student begins to exhibit off-task behavior. The next step is for the teacher to then redirect students' behavior if it continues after the reminder has been given. Following reinforcing, redirecting and reminding the student to follow the procedure or rule, the teacher may then implement an appropriate consequence that again, reinforces the appropriate procedure to be followed. These consequences may include:

- a written behavioral reflection

- one on one discussion with the student away from the group

- time away from activity to reflect on choices made

- contact of a parent for a conference (after you have tried the above)

- contact of an administrator in extreme situations 
Notar, C. E., \& Sorbet, S. R. (2020) The Bridge to Learning Is You The Teacher! Advances in Social Sciences Research Journal, 7(4) 462-482.

\section{Fostering Intrinsic Motivation}

\section{CONSTRUCTING THE SUPERSTRUCTURE}

How does one motivate students? This is not an easy task but techniques that work well in one situation may be useless in another. Incentives that create enthusiasm in some individuals in a class leave others completely indifferent. As a rule, the best motivational strategies are positive in nature. What happens in the learning environment can be divided into three types: (a) prior knowledge and experiences of life outside of the classroom, (b) the teacher's knowledge base, and, (c) anything that the student can read, see, or hear. Establish a good learning environment and present instruction in a professional manner. A competent and enthusiastic teacher is a positive influence on students. The classroom atmosphere can make the difference between motivating an enthusiastic learner or creating negative feelings toward a particular subject.

The ideal classroom climate supports an active partnership between the subject and the students. It includes five components: (a) Communication is open and active, featuring dialogue rather than monologue. (b) High levels of attraction exist for the group as a whole and among its members. (c) Norms are supportive for getting work done, as well as for optimizing individual opportunities to be different. (d) Members share high amounts of potential and influences all involved. (d) The processes of working and developing together as a group are important in themselves and open to examination and change. Motivation starts with prior knowledge and experiences of life outside of the classroom. The following methods are positive approaches that generally instill intrinsic motivation in the classroom:

\section{Show the relevance.}

The authors have heard that if it is on the test then it is relevant or a need. While that may be true, retention of the material learned for a specific test may be immediately lost after the test. Regardless of grade level, the reasons why we need to learn is a students' key question. Connecting student learning with authentic usage in their modern world is a key motivator to them experiencing the future need for the topic at hand.

\section{Plan for success.}

Plan instruction that is interesting to the students and is directed toward the intended learning outcomes. State objectives of the lesson and tell why they are important. Set appropriate standards of achievement that are developed upon set realistic goals based on where your students are at the point of instruction. Reduce anxiety by providing for early success that builds on students' selfesteem through attainment of the standards while providing a pleasant, physical environment. Nothing keeps students more on task than keeping them interested in something you are doing. Creating lessons and activities that will stimulate them and engage their interest will prove to be more effective than disciplining students. Whatever you decide, provide suitable reinforcement and encourage effort. Give credit and rewards in recognition of accomplishments and determine each students' accomplishment level based on where they started.

\section{Promote beliefs in competence.}

Be a model of enthusiasm for your students. If you are excited about the subject you are teaching, then your students will see the importance and your enthusiasm will be contagious. Interact with your students by providing positive and immediate academic feedback. Focus on the work being done and give positive feedback to support the work they are doing, rather than positive comments 
regarding them as a person. An example of this may be; "I see the way you are working diligently on your writing this morning," rather than "I love the way Terrence is writing." The first quote is focused on academic feedback and no one student feels favored over the other. The second quote may make Terrence feel singled-out and other students may not take too kindly to Terrence after a statement such as this is made.

\section{Induce and arouse curiosity.}

Make classes interesting. Add variety and playfulness to your courses. Increase student's active involvement in the classes you teach. A great many lessons roll over to more than one class sitting. When you first introduce the objectives in a creative way so as to "hook" your students, you will see immediately who is interested. It is up to the teacher to maintain that level of interest. Build on both intrinsic and extrinsic motives, but remember to foster the intrinsic motivation that comes from within. Rewards such as feelings of success, positive self-image, gaining self-respect and the respect of others are goals for all students. Aim for self-discipline \& autonomy in all students. The best reward is the satisfaction of a job well done. Extrinsic motivators such as material rewards like candy, stickers, treats are to be used only on occasion. The use of competition is another type of motivator but be mindful of always reducing comparisons and avoiding resentment of winners (Yunker, 1999-2000).

\section{Engaging the Learner}

\section{POURING THE SLAB}

Teachers must be provocative, relevant, engaging, interesting and provide depth and breadth within the content. But why are you teaching? The central questions in education deal with retention of learning and the transfer of the learning. How is that achieved? The teacher should relate established principles to advanced requirements. As a minimum, the teacher should periodically inform students how previous material relates to current subject matter. Students will more accurately remember the material that relates to job performance if they understand the relationship. Also, using what is learned promotes retention. Knowledge must be applied or it will be forgotten. Figure 3 provides the Contributing Factors to a student Meaning-Making of information.

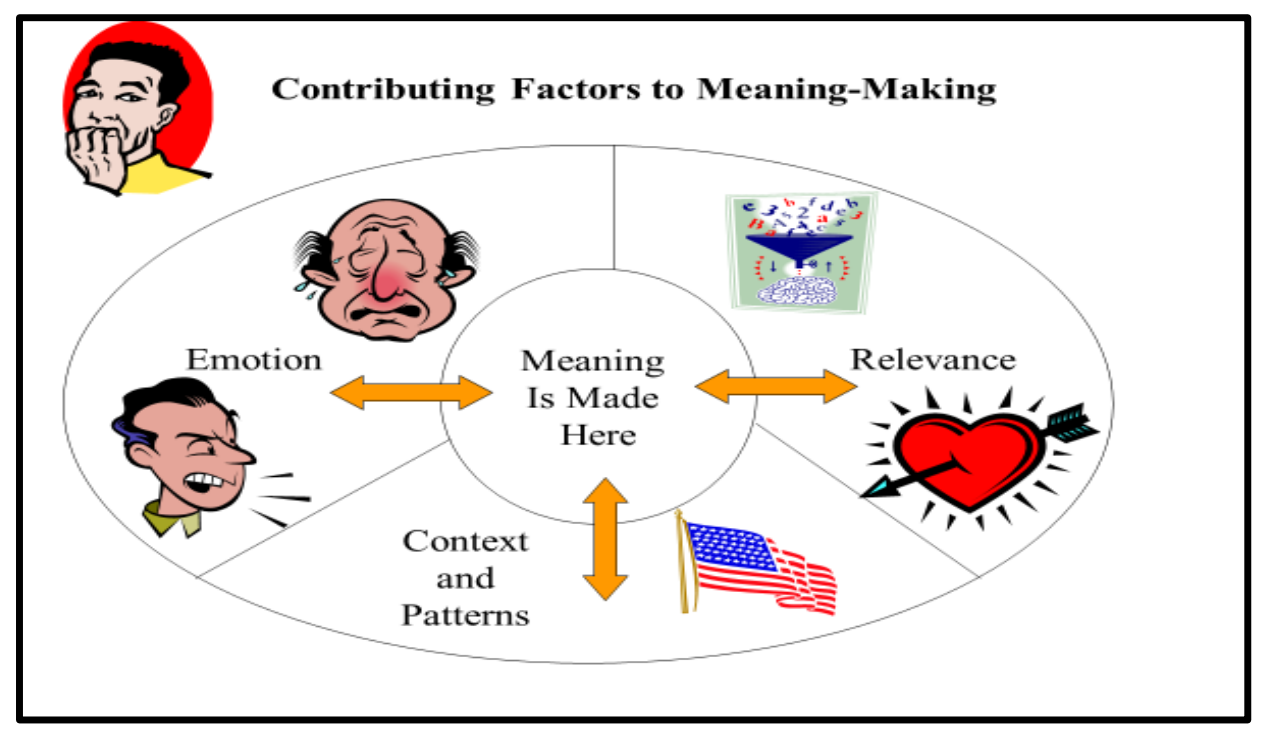

Figure 3: Contributing factors to meaning-making for students by Notar, JSU ESE 421. 
Learning and retention are based on remembering. what the student already carries in his head or experiences in his life outside the classroom. The three ways to retain information are through: recollection, recall, and recognition. Recollection is the ability to reestablish an earlier personal experience on the basis of a partial clue. Recall is the human ability to perform some activity in the present based on past learning. An adult can use recall to swim although he may not have done so since childhood. Recall differs from recollection in that the person cannot remember the circumstances under which something was learned. Recognition means to become aware of someone or something as familiar. It may be the way a person walks, the pitch of his voice or his accent. In such a case, the memory will generalize from familiar to similar (Akpan, et al., 2019).

Through these authentic connections to what is relevant to their lives, students can connect what is learned through the teacher scaffolding the information. For example, provide well-distributed practice in problem solving. Problem solving is an exercise in transfer because the student relates his knowledge to a problem and as upper-level content is received the student then builds on the basic problem solving skills already learned. When applied to real-world situations that the common person would use in a daily routine, students begin to realize the need for developing such problem-solving skills.

The more a student can apply learning to their "real-world" or visualize the relevance to themselves, the more retention and transfer will take place. Wherever possible move to the direct, purposeful experience.

Figure 4 shows the Cone of Experience. This model emphasizes application of knowledge and relates material to situations the student will encounter in the real-world. Classroom discussions and activities should be reflected in this connection. A word is great, a picture is better, but the ultimate learning opportunity is actually being there and experiencing something first hand. For example, if a teacher is teaching a lesson on Rome a picture is at the most basic level of engagement. However, if a teacher provides a 3D interactive visit to Rome via the Internet the entire learning experience becomes more engaging and meaningful for the students. Through accommodating all various learning styles, teachers can provide authentic learning experiences targeted at each child's strengths and weaknesses. 


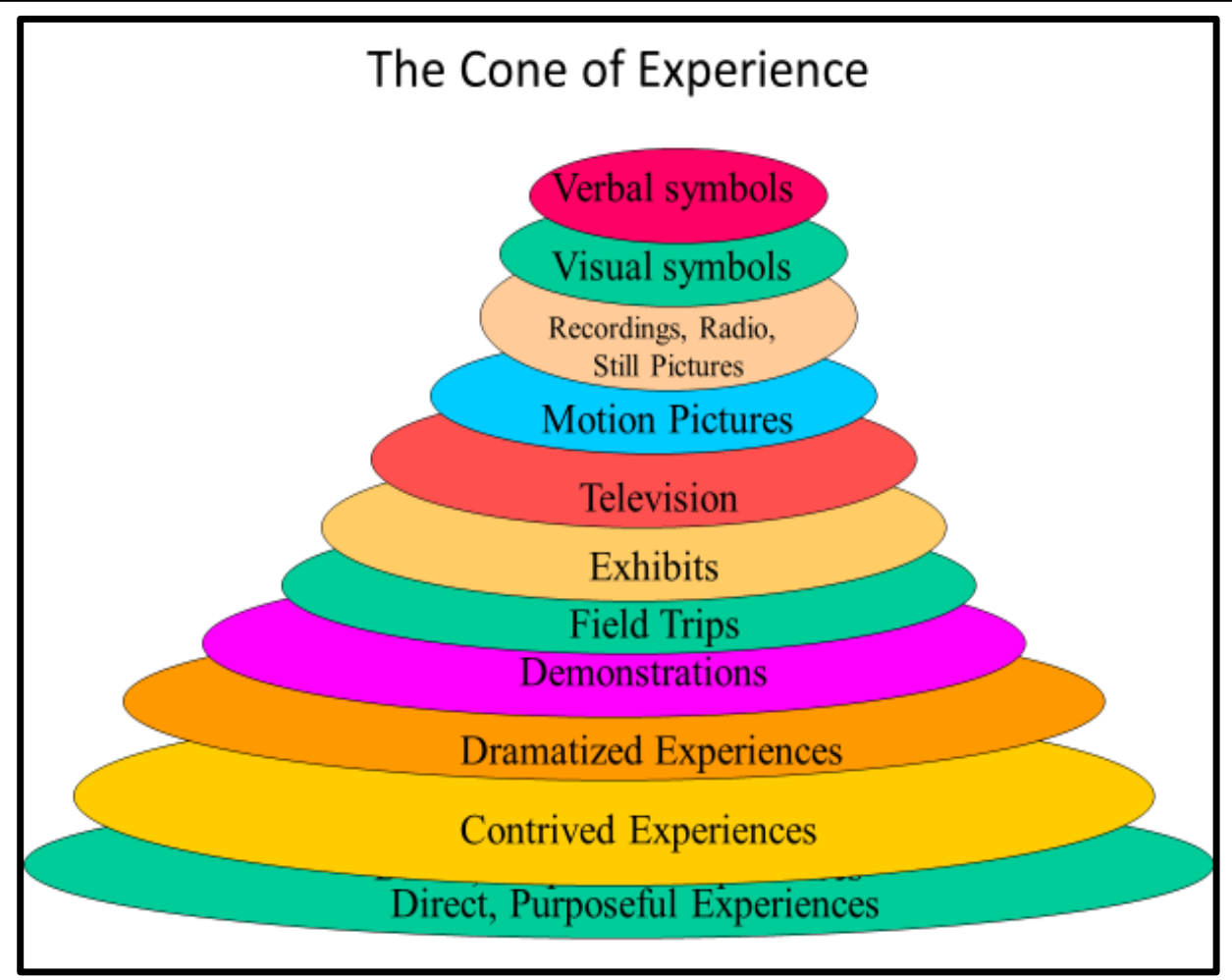

Figure 4: Edgar Dale and the Cone of Experience by Lee \& Reeves

Another example would be that Dr. Notar is a graduate of Penn State and he has told his grandson about being at a football game at the 100,000 seat stadium. They have even watched games on TV together. But it wasn't until his grandson was in a seat with the other 99,999 others that he had a true feeling of what his grandfather was talking about. It is up to the teacher to provide these authentic connections and experiences that intrigue learners and deeply connect their prior knowledge with the new content being presented.

\section{Learning activities}

When planning your lesson you must provide examples and activities that support and reinforce your objectives. Textbook is not the bible! In fact, due to budgetary constraints many classrooms do not have textbooks or are extremely outdated. Learning activities are not supplemental, they are the crux of a lesson. Figure 5 provides a good checklist of a quality learning activity.

The teacher's fundamental task is to engage students in learning activities that result in achieving learner objectives or outcomes. It is helpful to remember that what the student does is actually more important than what the teacher does. Meaningful activities engage students in active, constructive, intentional, authentic, and cooperative ways. Useful learning activities are ones where the student is able to take what they have learned from engaging with one activity and apply it in another context, or for another purpose. The Native American saying below explains it best in simple terms.

Tell me and I'll forget.

Show me, and I may not remember.

Involve me, and I'll understand. 


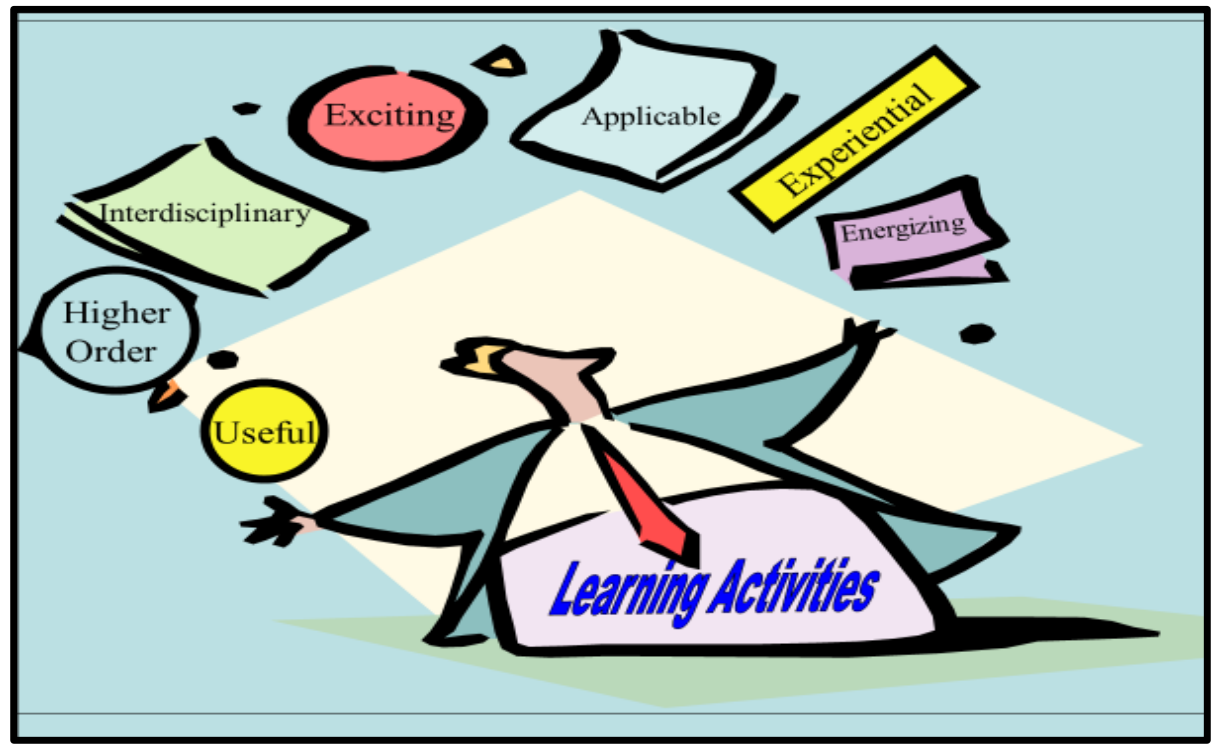

Figure 5: Learning activities by Notar, JSU ESE 421.

\section{Attaining objectives}

All instruction must have clearly defined goals, objectives, or intentions and must be made known to students at the beginning of instruction. When planning instruction. consider students' characteristics, attributes, preferences, and interests. While implementing the planned instruction, systematically and continuously monitor students' verbal and nonverbal behavior to determine the appropriateness of your instruction (e.g. puzzled or frustrated looks, inability to answer questions or to complete tasks. and student questions or comments that indicate a lack of understanding). When the planned instruction appears to be an inappropriate attempt to determine why and to identify alternatives, and when necessary, implement an alternative and monitor its effectiveness. Well-planned instruction begins with developing vocabulary. Many words that you will use have different meanings both in the dictionary and in your students' minds. You must establish the meaning for learning to take place. Too often instruction is relegated to facts, facts, facts. As mentioned previously, motivation provides examples both in historical and real-life application in the present. Learning will only be accomplished when an organizational pattern to content is provided. That organizational pattern should show interrelationships and be presented in an interdisciplinary approach whenever possible.

\section{Optimizing Instructional Time}

In revisiting routines and procedures we can recall that there is relatively little time for off-task behavior or class disruption. In most schools instructional time is finite, be it 55 minutes or a three hour block of time. Since time is of the essence, a teacher's lesson must be well-planned and implemented in an organized manner that informs students of the lesson objectives, identifies unfamiliar words before using them, and compares and contrasts similarities and differences between ideas being presented.

Teacher-led lessons are delivered step-by-step. Lessons should maintain a highly interactive instructional pattern, pose higher order thinking questions to all students, use variety, and convey enthusiasm to help keep students actively engaged. The teacher may provide examples that explain 
and support the concept or ideas being taught, drawing students' attention to new or important points and through reviewing them at appropriate points in the lesson. The teacher incorporates deliberate pauses that allow time for processing and reflection during which questions are posed. The students are provided with application exercises as a means of alternative assessment for the teacher to determine whether or not the student understands the information being taught.

The teacher should maintain a relatively brisk instructional pace, varying the pace as needed to accommodate learners and match the difficulty of the content. Carefully monitor students' work for understanding and when students do not understand, the teacher repeats main points, presents additional examples or explanations, or elaborating until the students achieve clear understanding. Plan more instructional material than you think you will need. If the planned lesson finishes early, use the remaining time to review with students. Avoid giving students "free time" or individual seat work $(8,9)$.

\section{Instructional Models}

Elementary school classroom students are typically engaged in active learning, however, as students progress into middle school, high school, and beyond, their teachers use less activitybased instruction and more "intellectual" classroom methodologies. For the most part the intellectual" classroom methodology is the direct instruction. Let's look at what direct instruction is and the other seven instructional models.

\section{Direct instruction}

is a method of teaching in which the teacher uses structured lessons with a specific goal. When teachers explain exactly what students are expected to learn, and demonstrate the steps needed to accomplish a particular academic task, students learn more. It rejects (or at least sets aside) the assumption that students will spontaneously develop insights on their own. Rather, direct instruction takes learners through the steps of learning systematically, helping them see both the purpose and the result of each step. The basic components of direct instruction are: (a) setting clear goals for students and making sure they understand these goals, (b) presenting a sequence of wellorganized assignments, (c) giving students clear, concise explanations and illustrations of the subject matter, (d) asking frequent questions to see if the students understand the work, and (e) giving students frequent opportunities to practice what they have learned (Notar, 2019).

\section{The Historical Method}

is a chronological presentation of a topic. However, the "new" historical method of instruction is the "historical method of research." The historical method of research is used when objects or occurrences are not here for us to directly observe, so we construct them from records or sources. This involves investigating, studying, understanding and explaining past events. This helps us to arrive at conclusions concerning causes and effects of trends of past occurrences, which help to anticipate or explain present or future events. In this method the sources must first be identified, located and selected. The sources then undergo analysis using external and internal criticism. Facts are then grouped or synthesized according to their nature and then are interpreted (Tjelle, 2016, 10). 
Notar, C. E., \& Sorbet, S. R. (2020) The Bridge to Learning Is You The Teacher! Advances in Social Sciences Research Journal, 7(4) 462-482.

\section{Concept Attainment}

is a strategy designed to teach concepts through the presentation of examples and non-examples. Students form, test, and refine hypotheses about the concept as examples and non-examples are presented. Then, they determine the critical attributes of the concepts - the characteristics that make the concept different from all others. Finally, students demonstrate that they have attained the concept by generating their own examples and non-examples $(4,7)$.

\section{Discovery, Inquiry/Inductive Model, Constructivist Model}

is a teaching technique that encourages students to take a more active role in their learning process by answering a series of questions or solving problems designed to introduce a general concept. In collaborative learning groups, the method of instruction used by the teacher/tutor is inquiry. Compared to didactic instruction and coaching, inquiry differs from its counterparts in one unique and very critical way: it immediately engages students with their own thinking processes. In other words, it teaches students to think for themselves instead of chasing the right answer.

\section{Constructivism}

is exposure to the world and children's activities cause them to construct mental precursors (schemata) to more fully-developed ideas (concepts \& structures) He felt that children's minds take such precursor components and continually construct more sophisticated ideas out of them (Notar, 2019).

\section{Cooperative Learning Model}

is a relationship in a group of students that requires positive interdependence (a sense of sink or swim together), individual accountability (each of us has to contribute and learn), interpersonal skills (communication, trust, leadership, decision making, and conflict resolution), face-to-face promotive interaction, and processing [reflecting on how well the team is functioning and how to function even better] $(1,5)$.

\section{Simulation Model}

is a model that replicates a system of processes, behaviors, and feedback that modify behaviors, reacting to feedback and closely resembling the real world. It is a logical model whose foundations emerge from an input-output systems analysis that can serve as a powerful tool for teaching. Simulation is not animation. Simulation must allow for interactivity between the model and the user as well as reactivity that permits changing variables affecting behavior and outcomes in the model (6, Larman, 2000).

\section{The Jurisprudential Model}

is an examination of political and social conflicts. The purpose of this model is to help students learn how to formulate defensible stances on public policy issues $(2,3)$.

When utilizing these instructional models of instruction, the teacher should follow a classroom developmental schedule. Sequencing is based on the students' adherence to procedures or routines and the students' acceptance of responsibility of the classroom, your interaction with students, and their progress within the content objectives. Figure 5 represents a suggestion of the timeline or tentative sequence of when to first introduce and use these instructional models in the classroom. 
Tentative Sequence of When to First Introduce and Use Instructional Models

$1^{\text {st }}$ six weeks: Direct Instruction Model

$2^{\text {nd }}$ six weeks: Historical Model*

$3^{\text {rd }}$ six weeks: Concept Attainment* and Cooperative Models

$4^{\text {th }}$ six weeks: Inquiry, Inductive, Discovery

$5^{\text {th }}$ six weeks: Simulation Model*

$6^{\text {th }}$ six weeks: Jurisprudential Model*

*Educational psychologists consider these teaching

strategies

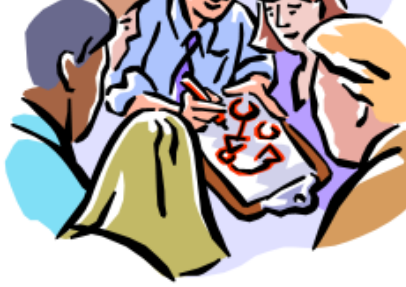

Figure 6: Introduction of Instructional Models by Notar, JSU ESE 421.

Mentioned above is students' acceptance of responsibility of the classroom and your interaction with students. Figure 7 shows the three student interactions in teaching. You can see the sequence in the figure corresponds with the sequence of the models.

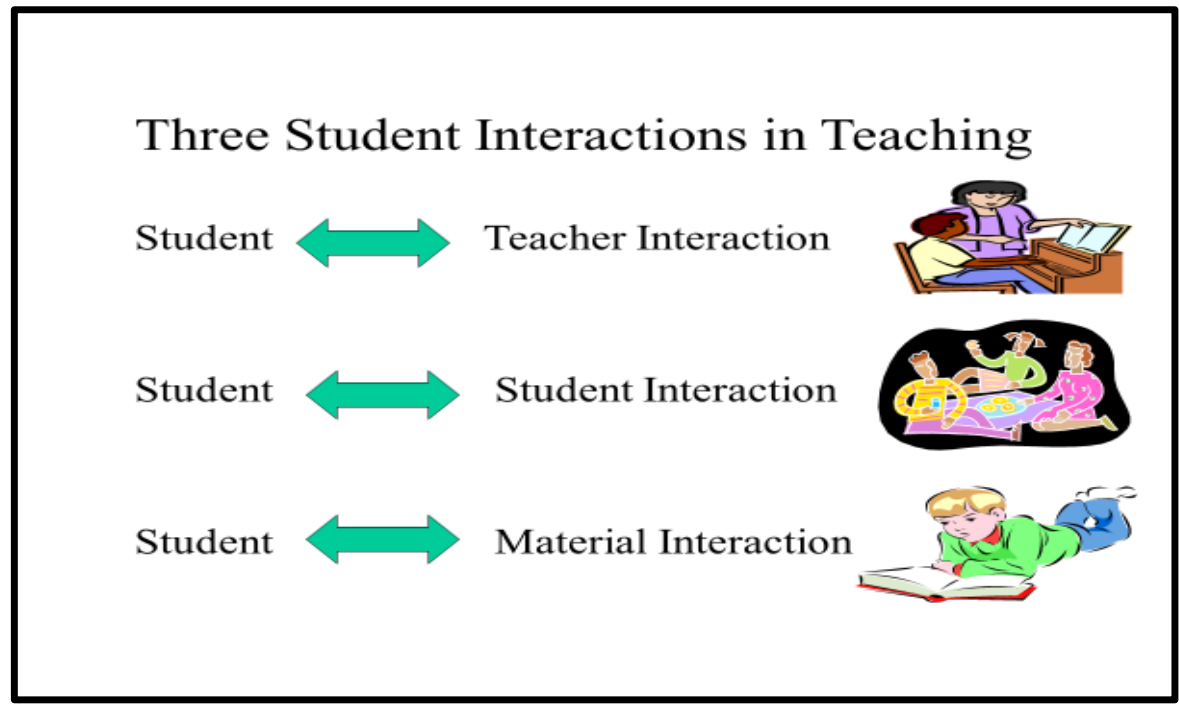

Figure 7: Student interactions in teaching by Notar, JSU ESE 421.

In any k-12 classroom there is a period of time when a classroom can go from teacher-centered to student-centered. Teachers in today's classroom want students to have an active role in their own learning. Higher levels of thinking require the teacher to be a tutor, mentor, and a resource person. These teacher roles can be instituted when students accept their role and responsibility in learning. The first 6-12 weeks establish the procedures, rules, and the roles that the students must accept in order to transition from teacher-centered instruction to student- centered instruction. The 
Notar, C. E., \& Sorbet, S. R. (2020) The Bridge to Learning Is You The Teacher! Advances in Social Sciences Research Journal, 7(4) 462-482.

instructional models in figure 6 are sequenced to allow for scaffolding of less teacher-centered instruction and more student-centered instruction.

\section{Organizational Patterns of Content}

Teachers can utilize a variety of patterns to organize content in order to best deliver the material in ways that are easily understandable for students. Teachers should consider grade level and the depth and breadth of the content being presented first in order to best decide how to organize material to maximize student understanding in a way that makes sense and is age-appropriate (The following organizational patterns references are Notar \& Barkley, 2009; Patterns of Organization). Too often students become lost due to the teacher not being organized in the presentation of the content in a course. This may result in an instructional error. These errors can be summed up as instructional errors in continuity. These errors affect the student's learning. The four types of instructional errors are: (a) thrusts - suddenly interrupting an activity without warning, (b) dangles - leaving them hanging while you take too long to set up, (c) flip flops - switching back to an old activity once you have started a new one, and (d) fragmentations - moving a group piecemeal, part of the class at a time. There are many organizational patterns that provide organization of the content within the model chosen to convey the knowledge of the subject for learning to take place. Learning and retention take place through organization.

\section{Time/Chronological Pattern}

Our vocabularies are filled with words referring to time; now, tomorrow, yesterday, today, sooner, later, earlier, last week, a month from now, 4 years ago, next time. Major events in our lives are organized by time: births, engagements, marriages, deaths. Time, or the chronological pattern of lesson organization, is a natural way of arranging events in the sequence in which they happen. This is sometimes called sequential organization. Certain processes, procedures, or historical movements and developments can often be explained best with a time sequence pattern. Rather than looking forward in time from a given moment, the strategy might be to look backward from a point of time. Regardless of which strategy is used, the flow of the lesson and transitions should make the chronological relationships between main points clear to the students.

\section{Order in Space}

A spatial or geographical pattern is often effective in describing relationships. In this pattern, the lesson material is developed according to some directional strategy such as east to west or north to south. With lessons about objects, the strategy might be to arrange the main points from top to bottom or bottom to top. A fire extinguisher might be described from top to bottom, an organizational chart from the highest ranks to the lowest, a library according to the services found on the first floor, then the second, and finally those on the third. Sometimes, the strategy is to organize the lesson from the center to the outside. In all lessons arranged spatially, each aspect or main point should be introduced according to some strategy. Just as with a lesson organized by time, the subject matter and the transitions should include elaboration and clarification of how the main points relate to one another. A simple listing of the various objects or places without explaining how they are related may confuse the students and make the points harder to remember.

\section{Cause/Effect}

A cause/effect pattern of organization is used in a lesson where one set of conditions is given as a cause for another set. In such lessons you may use one of two basic strategies to arrange the main 
points. With a cause/effect strategy, begin with a given set of conditions and show that these will produce or have already produced certain results or effects. Few things result from a single cause. There may be several causes and they may not act independently. Their effect may be greater or less than the sum of their parts. Lack of safety features on automobiles does not by itself cause more highway accidents, but the combination of careless driving and unsafe highways may account for many highway accidents.

\section{Problem/Solution}

This pattern presents students with a problem and then proposes a solution. With this pattern you must show that there is a problem and then offer corrective action that is (1) practical, (2) desirable, (3) capable of being put into action, and (4) able to relieve the problem. If the students are not aware of the problem or need, describe the exact nature of the problem. Sometimes when students become aware of the problem, the solution becomes evident, and little time is needed to develop the solution in the lesson. At other times, you need to spend time developing both the problem and the solution. Whatever strategy is used, with the problem/solution pattern students must know that there is a problem before they agree on a solution.

\section{Pro/Con}

The pro/con pattern, sometimes called the for/against pattern or advantages/disadvantages pattern, is similar to a problem/solution pattern in that the lesson leads to a conclusion. A major difference, however, is that an equal amount of attention is usually directed toward both sides of an issue with a pro/con pattern. When deciding the specific strategy to use with the pro/con pattern and determining how much time to spend on each, the following guidelines may be helpful: (a) giving both sides fairly even emphasis is most effective when the weight of evidence is clearly on the favored side, (b) presenting both sides is more effective when students may be initially opposed to the school solution, (c) presenting only the favored side is most effective when students already favor the school solution or conclusion, and (d) presenting the favored side last is generally more favorable to its acceptance, especially if the unfavorable side is not shown in too strong a light.

\section{Topical}

A topical division of the main points of a lesson involves determining categories of the subject or lesson objective. This type of categorizing or classifying often springs directly from the subject itself. Other topically organized lessons might follow strategies of known to unknown, general to specific, or specific to general. The number of strategies for arranging topical main points is practically infinite. The important consideration, as with any pattern, is that you give thought to the strategy of arrangement in order to improve student understanding and learning.

\section{Simple-to-Complex}

The simple-to-complex pattern leads the students from simple facts, or ideas, to an understanding of involved phenomena or concepts. In biology, for example, the students study the simplest form of life, then the intermediate forms, and finally, the more complex organisms. In studying jet propulsion, the students might first consider the action involved in releasing air from a balloon and finish by taking part in a discussion of a complex gas turbine. 


\section{Known-to-Unknown}

By using something the students already know as the point of departure, you can lead them into new ideas and concepts. In other words, you should move the student from information with which they are familiar with, towards unfamiliar information. For example, in developing the theory of flight, explain flight in the atmosphere before proceeding to flight in outer space.

\section{Procedural}

Step-by-Step or process method are other names for this organizational pattern. This pattern is used when there is only one way to go from start to finish. If you are told to count to 10 by twos you can only say $2,4,6,8,10$ and be correct. Changing a flat tire is also procedural.

\section{Whole-Part-Whole}

This pattern is useful for teaching an item of equipment or the organization of a police department. Descriptions of component parts are more easily grasped if the students know the function of the entire item and how the component parts add to the performance of the item. The function of one part of a police department is better understood if the students already know the missions of the parent part. From a description of the whole to a description of the parts does not complete the lesson. At least in the summary, the parts should be reintegrated back to the whole as a review of the items of equipment or organization.

\section{Comparisons}

A comparison is a bridge, built by the speaker, between the known and the unknown. The new thing or idea can be clarified by pointing out its resemblance or similarity to a familiar subject, idea, or situation. Comparisons can be factual or imaginary. Generally, the factual comparison can set the stage for the transfer of learning in the mind of the student. In a comparison, the description often becomes more graphic when you place an unknown or little understood item beside a similar but better known item. Contrast is a special form of comparison. For instance, showing how today's standard of living differs from that of a generation ago clarifies and explains a point by showing contrast or differences. Venn diagrams combine both comparisons and contrasting in a visual model representation. Venn diagrams act as a visual model or graphic organizer which displays all similarities, differences and commonalities when comparing two ideas. This diagram is first introduced in early elementary grades and is a graphic organizer that is revisited and utilized throughout all grade levels.

\section{Statistics Statistics}

They are probably the most misused and misunderstood type of verbal support. Wisely used, statistics can help teachers clarify their ideas. Statistics are also the most powerful support you can use. Not all figures, however, are statistical; some are simply numbers. Statistics show relationships (largeness or smallness, increases or decreases) or summarize large collections of facts or data. Before you use statistics, there are some questions to ask: (a) Are the statistics recent? (b) Do the statistics indicate what they purport to? (c) Do the statistics cover a long enough time to be reliable? (d) If the statistics are drawn from a sample, does the sample accurately represent the group to which you are generalizing? (e) When statistics report differences, are the differences significant? (f) When comparing things, are the same units of measure used to make the comparison? (g) Do the statistics come from a reliable source? (h) Are the statistics presented in the manner that best aids student understanding? 


\section{Combining Patterns}

If you use a single pattern to organize the main points, the lessons will make more sense. You will be able to remember more readily what the main points are when you teach the lesson. Even more importantly, students will be able to follow the lesson more easily and retain the material that has a single, logical pattern or organization. While you may choose a certain organizational pattern for the main points, consider using different patterns for subpoints. The important thing to remember is that each set of main points or subpoints should follow a given pattern of organization. Strive to organize the lesson in a way that will help present the information to the students in the most meaningful fashion. As you construct the outline, do so with the students' needs in mind.

\section{Instructional Models and Organizational Patterns}

An example of utilizing these instructional models and organizational patterns together in a secondary history lesson may be that the teacher uses a combination of historical and direct instructional models through combining patterns with cause and effect as the main focus. This history teacher may use chronological organization to set the action that caused and effected the Civil War. In order for the students to have concept attainment, pros and cons may be utilized to develop a problem and a solution. To further discuss or dig deeper the teacher may use statistics in topical organization. Since there is generally interest of students in the battles of the Civil War, slavery, and where the war fit into world history, the teacher may use inquiry, simulation, and jurisprudence through topical, problem solution and statistics. The key point here is for the teacher to remember that on any one topic, not all organizational patterns can, will, or should be used.

\section{Feedback and Self-Reflection}

\section{FINISHING TOUCHES}

To meet the demands of today's complex classrooms, you must be willing and able to accept feedback and self-reflect. Reflection provides a sense of personal responsibility for learning and improvement. Reflection provides a variety of perspectives to draw on in addressing the many challenging and complex components of teaching. It provides new knowledge and understandings that have immediate applications because they are created within the context of teaching.

Student learning is linked to the learning of their teachers. When teachers reflect on their practice, conditions are created to improve teaching. Self-reflection provides insight for the teacher to determine where they did not explain fully or where they may not have illustrated to the satisfaction of the students. Self-reflection shows where students made mistakes, and most importantly, where you as the teacher need to review and reteach your students to correct any misconception.

Your professional growth and satisfaction as a teacher will, in part, be linked to the ability to selfreflect on which practices worked well within your classroom and which ones need revising and restructuring. Through ongoing formal and informal assessments of your students, the teacher can utilize student progress to determine best practices in instruction to continue to use (Hollis, 2014; Jimenez, 2015).

\section{Professional Responsibilities as a Teacher}

So much can be written about your responsibilities as a teacher. A teacher is a role model. Your professional responsibility as an educator for your students remains at the highest level of setting 
Notar, C. E., \& Sorbet, S. R. (2020) The Bridge to Learning Is You The Teacher! Advances in Social Sciences Research Journal, 7(4) 462-482.

good examples. A teacher must maintain good personal appearance and exemplify a good attitude in order to encourage a good attitude from your students. Select your own teaching style that is natural, and projects your sincerity, confidence, and spontaneous nature. Your voice and speech should be delivered in a conversational tone. Use eye contact and physical attention when talking to students and BE FAIR to all students.

As a teacher you are the motivator for your students. Bring your enthusiasm for the subject or content area in which you are teaching. Be knowledgeable of your content area and material as well as the objectives and sequence of the lessons being taught. Develop students' vocabulary and explain content through an interdisciplinary approach based on clear, logical organizational patterns to content. Provides both historical and current authentic applications that demonstrate interrelationships and reinforce learning.

As a classroom teacher one should remember to build on the teacher and student relationship and avoid: (a) bluffing or empty threats, (b) using profanity, (c) using sarcasm or ridicule, (d) talking down or demeaning students, and (e) losing patience.

\section{CONCLUSION}

Teachers in today's classrooms are called to "build a bridge" in order to best meet the needs of their students. Through organization, creation of procedures and rules, fostering intrinsic motivation in students, providing engaging lessons, organizing information and paying careful attention to the manner in which instruction is delivered while adjusting along the way are just some of the steps taken by classroom teachers.

Well-planned and thoughtfully organized classrooms constructed with a foundation of supports, allow teachers to provide a variety of meaningful learning experiences for students to be successful. Teachers must also be willing to accept feedback and engage in self-reflection in order to best adjust lessons and management techniques throughout the school year.

Instruction that is exciting, cogent, and delivers in a sense that students will engage, will decrease the requirement to discipline students. That assumption and the years of experience of the authors have been proved true in the K-12 classroom and in higher education.

\section{References}

Akpan, J., Notar, C. E., \& Beard, L. (2019). Learning and retention or how learning and retention impact academic success. International Journal of Social Science and Business, 4(2), 1-6.

Burden, K., Kearney, M., Schuck, S., \& Burke, P. (2019). Principles underpinning innovative mobile learning: Stakeholders' priorities. TechTrends: Linking Research \& Practice to Improve Learning, 63(6), $659-668$.

Classroom Learning Activities Center for the Enhancement of Learning \& Teaching. (2010). Classroom learning activities. Retrieved from

file:///C:/Users/Charles\%20Notar/AppData/Local/Microsoft/Windows/INetCache/IE/HEANZM44/activelearningti psheet_march2010.pdf

Cruickshank, D. R., Jenkins, D. B., \& Metcalf, K. K. (2006). The Act of Teaching. (4th). Boston: McGraw Hill, $380-381$.

Darch, C. B., \& Kame'enui, E. J. (2004). Instructional Classroom Management (2nd ed.). Columbus, OH: Pearson/Merrill Prentice Hall. 
Davidson, J., Isom, A., Mitchell, A., Roper, J., Shelton, K., Uline, C., \& Notar, C. E. (2007). Pumped: Motivation as the foundation for learning, a review of research literature on motivation and who is responsible for it. Asian Social Science, 3(11), 128-131.

Denton, P. (2013). The power of our words: Teacher language that helps children learn. (2nd ed.). Center for Responsive Schools, Inc.,

Dillion, R. (2018). Room for improvement: Becoming more intentional about classroom design can help teachers manage behavior, build community, and improve learning. Educational Leadership, 76 (1), 40-45.

Emmer, E. T., Evertson, C. M., Sanford, J. P., Clements, B. S., \& Worsham, M. E. (1984). Classroom management for secondary teachers. Prentice-Hall, Inc., Englewood Cliffs, New Jersey 07632

Epanchin, C., Townsend, B., \& Stoddard, K. (1994). Constructive classroom management: Strategies for creating positive learning environments. Pacific Grove, CA: Brooks/Cole Pubishing Co.

Grossman, J. B. (2002). The test of time: Predictors and effects of duration in youth mentoring relationships. American Journal of Community Psychology, 30(2), 199-219.

Hollis, K. (2014). Benefits of critical reflection - what are the outcomes produced by CR? Retrieved from https://kristinahollis.wordpress.com/2014/05/13/benefits-of-critical-reflection-what-are-the-outcomes-producedby-cr/

Jimenez, R. (2015). Why Reflect? The Role of Reflection in the Learning Process - Tip \#68. Retrieved from https://vignettestraining.blogspot.com/2015/10/why-reflect-role-of-reflection-in.html

Larman, C. (2000). The System Behavior Model: What it does. Retrieved from https://Lee, S. J., \& Reeves, T. C. Foundations of learning andinstructional design technology: Chapter 7 Edgar Dale and the Cone of Experience. Retrieved from https://lidtfoundations.pressbooks.com/chapter/edgar-dale-and-the-cone-of-experience/

Lester, R. R., Allanson, P. E., \& Notar, C. E. (2017). Routines are the foundation of classroom management. Education, 137(4), 421-435.

Levin, J., \& Nolan, J. F. (2014). Principles of classroom management: A professional decision-making model. (7th ed.). N.Y.: Pearson.

Lucariello, J. M., Nastasi, B. K., Dwyer, C., Skiba, R., DeMarie, D., \& Anderman, E. M. (2016). Top 20 psychological principles for PK-12 education. Theory into Practice, 55(2), 86-93.

Mertler, C. A. (2003). Classroom assessment: A practical guide for educators. Los Angeles: Pyrczak Publishing, 7.

Murray, K. (2018). Adding a little classroom magic for learning: Creating spaces to promote student engagement. Teachers Matter, 40, 6-8.

Notar, C. E., \& Barkley, J. M. (2009). Lesson organization: Big vision step-by-step execution. Education, 130(2), 163171.

Notar, C. E., Uline, C. S., \& Eady, C. K. (2008). What makes an "effective" leader: The application of leadership. International Education Studies, 1(3), 25-29.

Notar, C. E. (2019). Authentic education, competency-based learning, differentiated instruction, experiential education, learning/student-centered learning, performance-based education, proficiency-based learning. International Journal of Social Science and Business, 4(2), 114-132.

Patterns of Organization. Retrieved from http://faculty.washington.edu/ezent/impo.htm

Persaud, C. (2018). Instructional strategies: The ultimate guide. Retrieved fromhttps://tophat.com/blog/instructional-strategies/

Smaldino, S. E., Russell, J. D., Heinrich, R., \& Molenda, M. (2005). Instructional technology and media for learning. (8th ed.). Columbus, $\mathrm{OH}$ : Pearson Merrill Prentice Hall.

Suits, B. K. J. (1983). Redirection of student attention using verbal and nonverbal cues. A thesis submitted to the Division of Curriculum and Instruction in partial fulfillment of the requirements for the degree of Master of Ed. in Reading. University of North Florida College of Education. April, 1983. 
Notar, C. E., \& Sorbet, S. R. (2020) The Bridge to Learning Is You The Teacher! Advances in Social Sciences Research Journal, 7(4) 462-482.

Taylor, C. S., \& Nolen, S. B. (2005). Classroom assessment: Supporting teaching and learning in real classrooms. Columbus, OH: Pearson/Merrill Prentice Hall

Tjelle, H. (2016). What is the historical method and how does it compare to the scientific method? Retrieved from https://www.quora.com/What-is-the-historical-method-and-how-does-it-compare-to-the-scientific-method

Yunker, B. (1999-2000). EPY 332, Curriculum Guide: Motivate. Jacksonville State University.

Wong, H. K., \& Wong, R. T. (2009). The first days of school: How to be an effective teacher. Mountain View, CA: Harry K. Wong Publications.

1 Chapter 1 - Overview of Cooperative Learning. Retrieved from

file:///C:/Users/Charles\%20Notar/AppData/Local/Microsoft/Windows/INetCache/IE/VVT924HV/CoopLearningHa ndbook1999.pdf

2 Legal Dictionary. (2014) Jurisprudence. Retrieved from https://legaldictionary.net/jurisprudence/

3 Pam, N. (2013). Jurisprudential teaching model. Retrieved from https://psychologydictionary.org/jurisprudentialteaching-model/

4 Brinpop Educators. Concept attainment learning strategy. Retrieved from https://educators.brainpop.com/teaching-tip/concept-attainment/

5 Explanations of and Assessments in Cooperative Learning. Retrieved from http://wh-magazine.com/educationalphilosophy/explanations-of-and-assessments-in-cooperative-learning

6 Anylogic. Why use simulation modeling? Retrieved from https://www.anylogic.com/use-of-simulation/

7 Mondal, S. Bruner's concept attainment model. Retrieved from https://www.slideshare.net/Sahin12/conceptattainment-model-42987280

8 pedagogiayandragogia2016. Classroom management stategies. Retrieved from https://sites.google.com/site/pedagogiayandragogia2016/classroom-management-stategies

9 Edgenuity. The role of the teacher in a blended learning classroom. Retrieved from

file:///C:/Users/Charles\%20Notar/AppData/Local/Microsoft/Windows/INetCache/IE/KNM25PCC/Role-of-theTeacher.pdf

10 Kumar, M. Historical method in research. Retrieved from https://www.slideshare.net/manukumarkm/historicalmethod-in-research

11 pbisworld. Non-Verbal cues \& signals. Retrieved from https://www.pbisworld.com/tier-2/non-verbal-cuessignals/

12 theteachertoolkit . Non-Verbal signals. Retrieved from http://www.theteachertoolkit.com/index.php/tool/nonverbal-signals

13 Garrett, S. Proximity control in the classroom: Meaning \& strategy. Retrieved from https://study.com/academy/lesson/proximity-control-in-the-classroom-meaning-strategy.html

14 Davis, D. K. Top ten strategies for teachers. https://dkdavis.weebly.com/proximity-and-mobility.html 